\title{
Economic burden associated with alcohol dependence in a German primary care sample: a bottom-up study
}

\author{
Jakob Manthey ${ }^{1 *}$ (D) Philippe Laramée ${ }^{2}$, Steve Parrott ${ }^{3}$ and Jürgen Rehm ${ }^{1,2,4,5,6,7}$
}

\begin{abstract}
Background: A considerable economic burden has been repeatedly associated with alcohol dependence (AD) mostly calculated using aggregate data and alcohol-attributable fractions (top-down approach). However, this approach is limited by a number of assumptions, which are hard to test. Thus, cost estimates should ideally be validated with studies using individual data to estimate the same costs (bottom-up approach). However, bottom-up studies on the economic burden associated with AD are lacking. Our study aimed to fill this gap using the bottom-up approach to examine costs for $A D$, and also stratified the results by the following subgroups: sex, age, diagnostic approach and severity of $A D$, as relevant variations could be expected by these factors.

Methods: Sample: 1356 primary health care patients, representative for two German regions. AD was diagnosed by a standardized instrument and treating physicians. Individual costs were calculated by combining resource use and productivity data representing a period of six months prior to the time of interview, with unit costs derived from the literature or official statistics. The economic burden associated with AD was determined via excess costs by comparing utilization of various health care resources and impaired productivity between people with and without AD, controlling for relevant confounders. Additional analyses for several AD characteristics were performed.
\end{abstract}

Results: Mean costs among alcohol dependent patients were $50 \%$ higher compared to the remaining patients, resulting in $1836 €$ excess costs per alcohol dependent patient in 6 months. More than half of these excess costs incurred through increased productivity loss among alcohol dependent patients. Treatment for alcohol problems represents only $6 \%$ of these costs. The economic burden associated with AD incurred mainly among males and among 30 to 49 year old patients. Both diagnostic approaches were significantly related to the economic burden, while costs increased with alcohol use disorder severity but not with other AD severity indicators.

Conclusions: Our study confirms previous studies using top-down approaches to estimate the economic burden associated with AD. Further, we highlight the need for efforts aimed at preventing adverse outcomes for health and occupational situation associated with alcohol dependence based on factors associated with particularly high economic burden.

Keywords: Cost of illness, Alcohol dependence, Primary care, Costs, Economic burden, Germany

Abbreviations: AD, Alcohol dependence; APC study, 'Alcohol dependence in primary and specialist care in Europe' study; DSM-IV, Diagnostic and statistical manual of mental disorders, fourth edition; GPs, General practitioners; DSM5, Diagnostic and Statistical Manual of Mental Disorders, fifth edition; AUD, Alcohol use disorder; CIDI, Composite international diagnostic interview; WHODAS, World Health Organization Disability Assessment Schedule; K10, Kessler psychological distress scale; UKATT, United Kingdom Alcohol Treatment Trial

\footnotetext{
* Correspondence: jakobmanthey@snappyquest.org

'Institute for Clinical Psychology and Psychotherapy, TU Dresden, Chemnitzer

Str. 46, 01187 Dresden, Germany

Full list of author information is available at the end of the article
} 


\section{Background}

Alcohol dependence (AD) is a prevalent disorder in high-income countries, with $3.4 \%$ of the adult population in the European Union being alcohol dependent [1]. $\mathrm{AD}$ represents a major health burden for modern societies [2] because of high mortality rates [3-5], associated disability [6] and prevalent comorbidities [7-9]. The considerable health burden is also closely linked to an economic burden for the society. The economic burden is defined by the societal costs incurred by a given disease and is usually measured against a counterfactual scenario which assumes that the given disease does not exist [10]. The costs incurred by AD and heavy drinking were estimated to amount to about $1 \%$ of the European gross domestic product [11]. For Germany, the economic burden related to AD has not been estimated yet, but the burden associated with alcohol in total were also found to be around $1 \%$ of the national gross domestic product $[12,13]$.

While a number of other studies have estimated the economic burden of alcohol in the EU in general, and Germany in particular e.g. [12, 14-16], studies on the economic burden of $\mathrm{AD}$ are more sparse as indicated in a recent review [17]. The burden of $\mathrm{AD}$ was found to be related to direct health care spending, e.g. for hospitalizations and medications, as well as to indirect costs associated with unemployment and absenteeism. The authors call for more cost-of-illness studies as they identified several shortcomings in the data. More detailed estimates are necessary to justify public spending, e.g. for planning and implementing public health programs to reduce the burden of addiction.

Cost-of-illness studies usually lack empirical assessments of health care utilization and therefore combine aggregated data with alcohol-attributable fractions (top-down method) to determine the share of alcohol consumption or alcohol dependence in cause-specific mortality and hospitalizations [2]. However, this approach is limited by a number of assumptions. First, alcohol-attributable fractions denote the proportion of cases attributable to all alcohol consumption by definition, usually derived from the distribution of average drinking levels and associated relative risks [18]; thus, they cannot be used to evaluate costs related to certain drinking patterns or alcohol-related diagnoses without being adjusted to the relevant category e.g. [11]. Second, it is assumed that risk functions employed in the calculation of alcohol-attributable fractions, developed from published meta-analyses based on systematic literature reviews that included international literature, can be applied to specific countries. Third, aggregate data usually include a number of estimates of different sources and thus reproduce their measurement errors.
Cost-of-illness studies that collect individual data (bottom-up method) do not rely on these assumptions and have thus the advantage of directly calculating the economic burden, making them a benchmark against which other studies using the top-down method can be compared with. Additionally, unlike studies relying on aggregate data, studies employing the bottom-up method generally allow for a more detailed calculation and separation of costs for specific subgroups for which population-attributable fractions are not available. The economic burden of a given disease is estimated by comparing mean costs of diseased and healthy individuals, which results in excess costs. While this approach suits well to determine costs due to morbidity and disability, it can hardly assess costs related to mortality, which should be considered [10] as they make up a substantial share of the economic burden associated with AD [11].

To date, previous studies have used bottom-up approaches to estimate the economic burden for some diseases e.g. $[19,20]$; however, for $\mathrm{AD}$, studies using this method in sufficiently large and representative samples are very sparse [for a systematic review of international cost-of-illness studies, see [11], for reviews of European cost-of-illness studies, see [17, 21]. Thus, using a bottom-up approach, the present studies' primary aim was to estimate the economic burden of $\mathrm{AD}$ and to compare those estimates with previous top-down estimations, which suggest that indirect costs make up at least half of $\mathrm{AD}$ related costs in most countries $[2,11]$.

Previous estimates also indicated that $70 \%$ of the economic burden related to alcohol consumption in Germany were caused by males [12], which is very similar to the sex ratio in $\mathrm{AD}$ diagnoses [1]. However, as this proportion varied considerably across various cost categories, a sex-stratified examination of the economic burden was considered important. Similarly, age was regarded a relevant factor the economic burden because the course of $\mathrm{AD}$ peaks at early ages [22] and interactions of $\mathrm{AD}$-associated somatic comorbidities with age have been suspected [23].

For the purpose of estimating the economic burden associated with $\mathrm{AD}$, we analysed a sample of German primary care patients from the 'Alcohol Dependence in Primary and Specialist Care in Europe' (APC) study [7, 24]. We identified two important AD characteristics that could influence the economic burden associated with AD. First, previous reports of the APC study showed that patients diagnosed with AD either through a standardized instrument assessing DSM-IV (Diagnostic and Statistical Manual of Mental Disorders, fourth edition) diagnoses [25] or through clinical judgements from the treating general practitioner (GP) made up two relevant but largely distinct groups of alcoholics [7]. As GP diagnosed patients were older and reported more 
comorbidities than patients with DSM-IV diagnoses, separate cost examinations for both diagnostic groups seemed reasonable. Second, the AD associated economic burden was expected to vary by $\mathrm{AD}$ severity as measured by the number of DSM-5 (Diagnostic and Statistical Manual of Mental Disorders, fifth edition) alcohol use disorder (AUD) criteria [26], drinking levels [27], or treatment for alcohol problems [28] because these indicators were found to be related to adverse mental and/ or physical consequences as well as disability and mortality [4, 23, 28-30]. It may seem counterintuitive to consider alcohol treatment as indicator for severity but low treatment rates [31] and increased degree of impairment [32] suggest that only the most severe cases seek treatment. Given the associations with comorbidity, disability and mortality, it was expected that health care spending and impaired productivity would increase with AD severity. Thus, additional analyses should serve to measure the impact of the diagnostic approach and of different indicators of $\mathrm{AD}$ severity on the economic burden associated with $\mathrm{AD}$.

In conclusion, the present studies' primary objective was to estimate the cost-of-illness of AD patients, from a societal German primary care perspective using a bottom-up approach. The results were compared to previous estimates of German cost-of-illness studies of alcohol that used a top-down approach. In addition, this study stratified the results by sex and age, and performed additional analyses to examine the impact of $\mathrm{AD}$ characteristics (diagnosis and severity).

\section{Methods}

\section{APC study design and participants}

The APC study was designed to gain knowledge about the distribution, recognition, and treatment of $\mathrm{AD}$ in European primary health care settings. Previous results of the study indicate that AD among primary care patients was characterized by low socioeconomic status, unemployment, co-morbidities, mental distress, and disability [32]. For the study, a representative sample of GPs was drawn in six European countries (Germany, Hungary, Italy, Latvia, Poland, and Spain), after approval was obtained from the concerning ethic committees in all countries (Germany: approval gained on August 28, 2012; reference number: EK 207072012).

GPs assessed patients aged 18-64 on one day or more than one consecutive days using a brief questionnaire, which focused on the patients' health and included alcohol-related questions as well as present, and lifetime AD diagnoses. A probability sample of all assessed patients was then drawn while oversampling patients perceived to have alcohol problems or AD by their GP. Sampled patients were further interviewed using a range of standardized instruments including the Composite
International Diagnostic Interview CIDI; [33] which is the gold standard in assessing DSM-IV diagnoses [34]. It was previously shown that both CIDI and GPs diagnosed a similar proportion of individuals, with differences in age and comorbidities and overall little overlap between both groups [7]. As both approaches were judged valid, they were combined into a mutual AD category. Respective diagnoses were based on the 12-month time frame prior to the interview. The CIDI also assessed the patients' drinking behavior with a quantity-frequency approach [35], which could be combined to form daily drinking levels as measured in standard drinks per day (one standard drink equals $10 \mathrm{~g}$ pure ethanol).

Furthermore, the patient interview also included the World Health Organization Disability Assessment Schedule (WHODAS) 2.0 [36] to assess sociodemographic variables and the degree of disability, the Kessler Psychological Distress Scale (K10), and a service use questionnaire adapted from the United Kingdom Alcohol Treatment Trial (UKATT) [37], which can be found in Additional file 1.

The German population sample of the APC study was identified by primary health care GPs from the 'National Association of Statutory Health Insurance Physicians' ("Kassenärztliche Bundesvereinigung") (response rate at GP level: 36.7 \%) who were practicing in two German regions: Berlin-Brandenburg (46.1\% of all GPs) and eastern Saxony (53.9 \% of all GPs). Interviews with patients were conducted mainly via telephone (response rate at patient level: $75.7 \%$ ) between March 2013 and January 2014. All patients gave informed consent prior to being interviewed. A more detailed description of the APC study, its sampling design and instruments used can be found elsewhere [7, 24].

\section{Cost assessment}

In order to determine the costs for each patient, we combined individual resource use and productivity data with respective unit costs. For example, in order to determine the costs of GP visits, we multiplied the number of visits with the costs of a single visit. All resource use data was collected via the patient interview and included hospital attendances, general practice visits, home care by healthcare and support professionals, medication use, and alcohol services use. If respondents felt that their type of contact was not part of the provided categories, they could specify the number of 'other' contacts. Most of these responses could be classified into existing or new categories based on their specification. If the specification was missing, the contacts were not included in determining respective costs.

Additionally, productivity data was also assessed through the interview and encompassed questions on the patients' employment status and their absenteeism 
in the workplace. Most of these data were assessed using the UKATT questionnaire [37]. All questions in this instrument referred to a six months period prior to the interview, which was the default period in the original version of the questionnaire. We considered this period sufficiently long to gather important information about health care utilization and productivity, while being short enough to keep potential memory bias at a minimum.

These resource use and productivity data were then combined with German unit costs following a bottomup approach, in compliance with the guidelines of the 'Working Group Methods in Health Economic Evaluation', which lists standard unit costs for health economy evaluations in Germany [38]. The majority of unit costs could be taken from their publication, while the remaining unit costs were taken from statistics and publications by official agencies or health insurance companies. All costs were updated to 2014- $€$ using the consumer price index [39]. For health care unit costs, we used health care specific price changes; for costs related to productivity, overall price changes were used. Unit costs in $2015-€$ were deflated using the average rate from the first 10 months of the year 2015. A detailed description of all resource use components, their updated unit costs, and related sources are presented in Additional file 2: Web Table 1.

\section{Direct costs}

Hospital attendances For hospital attendance rates, we assessed up to three (limit given by UKATT questionnaire) department-specific inpatient admissions, outpatient visits, day case surgery attendances, and accident and emergency attendances. Unit costs were derived from the guidelines for health economic evaluation in Germany [38]. For inpatient and outpatient visits, we used department-specific unit costs and mean costs if department-specific unit costs could not be assigned to the reported department. In Germany, separate day case surgery attendances generally do not exist and were thus rarely reported by the patients $(6 \%$ with at least one attendance). Day case surgery and outpatient visits were valued alike. Unit costs for accident and emergency attendances were equal to mean inpatient admission costs for patients who were admitted to the hospital following the treatment. For patients who received treatment in the accident and emergency department only, the respective department-specific outpatient unit costs were used. Therefore, all hospital-related costs could be grouped as either inpatient or outpatient costs.

General practice visits We assessed the number of surgery and home visits, as well as practice nurse contacts (at the surgery) for each patient, while GP and nurse contacts were collapsed into a single category. Unit costs for personal patient contacts and home visits were taken from the standard evaluation criteria (Einheitlicher Bewertungsmaßstab) [40] - a catalogue on the costs of services reimbursed by the statutory health insurance to the respective health professionals. As appropriate in the German context [38], these costs had to be adjusted to the share of private health insurances in outpatient health care settings. For this reason, we updated the ratio of the share of patients covered by statutory health insurance [41] to the share of total revenue made by statutory health insurance companies [42], which resulted in a factor of 1.03 - smaller than the factor used by Krauth and colleagues [38] (1.11).

Home care by healthcare and support professionals In this section, we asked patients for the number of home contacts by health professionals, including occupational therapists, support workers, social workers, community psychiatric nurses, district nurses, and other professionals, where patients specified using the service of physiotherapists and alternative practitioners. Unit costs for these services were drawn from different sources: For services provided by occupational therapists, we referred to the mean cost of various services at the patients' home remunerated by different statutory health insurances in Berlin [43], after being weighted by the share of patients in the respective insurance companies [44], and adjusted with the above specified ratio for the share of private health insurances. Costs of a home session with a physiotherapist are based on the guidelines for health economic evaluations in Germany [38], and with a home visit charge added [45]. Unit costs for home visits from alternative practitioners were taken from a separate remuneration system which provides commonly used charges for different treatments [46]. Contacts with other health care professionals (e.g. social workers) were valued using the mean costs of occupational therapists, alternative practitioners, and physiotherapists. Lastly, the costs of paid homemakers providing household support were determined using the mean gross income of other labour forces [47].

Medication use For prescribed medication, we assessed brand names, size of each dose (in $\mathrm{mg}$ ), frequency of doses per day, and period of intake of up to five medications per patient (limit was predetermined by the UKATT questionnaire and was reached by $7.5 \%$ of all patients). The cost of each medication was determined by multiplying costs per day with period of intake. While period of intake was directly assessed, costs per day were based on costs per dose (estimated by identifying price and size of available medication packages in the red list [48] or online pharmacies) and the reported dose or, if 
missing, the defined daily dose [49]. Additional file 2: Web Figure 1 describes these steps in detail (see Additional file 2).

Taken together, two core variables were needed to calculate medication costs: a) medication costs per day multiplied with b) period of medication intake. This data was only available in association with $37 \%$ of all reported medications, mainly because the exact brand names were not given for $61 \%$ of all reported medications, but instead their prescribed purpose or another reference category (e.g. hypertension medication, contraceptive, etc.). Because assessment of costs per package without a valid trade name were not feasible, the respective costs per day were unavailable. Therefore, we imputed the costs per day by using the median of the respective costs of similar medications of the same category identified via the Anatomical Therapeutic Chemical' code. Using the median allowed us to impute conservatively and be less affected by outliers of very costly medications. A similar procedure was applied to missing values of period of intake (5.7 \% of all reported medications), for which the mean period was imputed among the same category of drugs. One case reported using a very costly drug (calculated costs: $315659.30 €$ in the 6-month observed period). In order to make sure that this outlier would not overly inflate the medication costs, we decided to adjust the costs to $150 \%$ of the second highest single medication cost (adjusted costs: $7328 €$ ).

Alcohol specific services use Alcohol specific individual or group contacts with GPs or their nurses, with alcohol agencies, at residential rehabilitation institutions, at hospitals, with self-help groups, and other contacts were assessed. All reported contacts were grouped into GP contacts, inpatient admissions (in residential rehabilitation institutions or hospitals), outpatient visits (at hospitals or alcohol agencies), counselling (at alcohol agencies, e.g. with psychotherapists) and group therapies. Alcohol-related GP contacts were valued as any other GP visit with unit costs taken from the standard evaluation criteria [40], and adjusted for the share of private health insurances (as described above). The unit costs for inpatient and outpatient treatment were retrieved from the hospital based remuneration system for psychiatry and psychosomatic departments, referring to the daily mean remuneration for inpatient and outpatient treatment of $\mathrm{AD}$, respectively [50]. Costs were determined based on the number of nights spent in the hospital or based on the number of semi-residential contacts, for inpatient and outpatients visits respectively. For alcohol counselling contacts, unit costs were based on contacts with psychotherapists and were taken from the German guidelines for health economic evaluations [38]. Unit costs of a single group therapy session were considered equal to the opportunity costs of one-hour leisure time of both the patient and the therapist. Opportunity costs were assessed via the gross average wage in Germany in 2014 [47].

\section{Indirect costs - productivity losses}

We considered absenteeism, unemployment, and disability or early retirement as indirect costs. First, respondents were classified as employed (paid work or selfemployed), unemployed (but job seeking), or disabled/in early retirement (including unemployment due to health reasons) based on responses given in the WHODAS 2.0 sociodemographic section. Patients pursuing non-paid work, studying, or homemaking in their own home were not assigned any productivity-related costs, representing $17.2 \%$ of all studied cases. The costs related to absenteeism among gainfully employed patients were estimated using the friction cost approach [51] and a frictional period of 49 days [38]. We referred to mean gross costs of one working hour multiplied with the mean working hours per day in 2013 [52] to assess the costs of one absent day. Costs related to unemployment could be retrieved from another study which took into account paid benefits, reduced tax revenue, and reduced insurance fees within statutory health and retirement insurances [53]. We manually estimated costs related to unemployment due to health problems, disability, or early retirement using the mean paid benefits for persons with reduced working capacity [54] in addition to costs of reduced tax and fee revenue per unemployed person according to the previously mentioned study [53]. This estimation assumes similar patterns of reduced spending among the disabled or early retirees compared to other unemployed patients. Although the classification of employment status only refers to the time of the interview, we generalized this classification to the six months prior to the interview in order to be in line with the other measures on direct and indirect costs. We did not include costs due to premature mortality because the design of this study did not allow for the assessment of this parameter.

In addition to calculating productivity-related costs, we also present descriptive statistics on presenteeism, i.e. reduced capacity while being at work. We did not include a standardized measure to directly determine the respective costs but collected information approximating this concept: number of days with reduced or cut-back work due to any health condition (WHODAS 2.0); number of days with at most half of the usual capacity due to mental distress (K10); number of days with affected productivity at work due to alcohol use (UKATT service use questionnaire). These measures are presented descriptively in order to grasp the magnitude of lost productivity while being at work. 


\section{Statistical analyses}

As contextual information, descriptive statistics for sociodemographic variables and the WHODAS sum score as indicator for disability were presented for patients with $\mathrm{AD}$ diagnoses and for those without. We tested for statistical differences by diagnostic status via negative binomial regression (for the WHODAS sum score) and via $\mathrm{Chi}^{2}$-Tests (for the remaining binary variables). The sampling design implied patients with alcohol problems or $\mathrm{AD}$ to be overrepresented in the interviewed sample. This distortion was accounted for by weighting all analyses with the inverse sampling probability.

\section{Primary aim: estimation of economic burden of $A D$}

The economic burden associated with $\mathrm{AD}$ was determined via excess costs, which were calculated as mean difference between patients with and without AD diagnosis by sex in the following sectors of direct and indirect costs: inpatient admission, outpatient visit, any GP visit, prescribed medication, home care, alcohol treatment, absenteeism, unemployment, disability/early retirement. Given the right skewed distribution of cost variables, significant differences were tested using ageadjusted negative binomial regressions for all count variables (most cost variables). Decisions for or against utilization of zero-inflated models for variables with excess zeros, i.e. resources being utilized only by a minority of patients, were based on results from Vuong tests and actual distribution. Zero-inflated models are nested models predicting both the occurrence of any costs (logit model) and the amount of costs (count model) [55]. Thus, these models identify reasons for higher mean costs by specifying whether (a) the proportion of patients using any service differs (logit model) or whether (b) there are any differences in the average treatment costs among those reporting at least one contact (count model). For costs associated with unemployment and disability/early retirement (binary/ordinal variables), we employed logistic regressions. Since costs related to disability/early retirement were sex-specific and thus resulted in an ordinal scale (0: no costs, 1 : mean costs for males, 2: mean costs for females), we used a binary variable indicating disability/early retirement in order to conduct a logistic regression in the entire sample. Age-stratified cost analyses were illustrated by plotting the estimated costs for five consecutive age groups of similar size $(18-29,30-39,40-49,50-59$, and 60-64). Sex-adjusted negative binomial regressions on the overall costs were run for each age group to examine the differential impact of age.

Further, descriptive measures on presenteeism were presented separately, as they could not be included in the cost estimations. Sex-stratified differences between patients with and without $\mathrm{AD}$ were tested by using ageadjusted zero-inflated negative binomial regressions for count variables (as above) and logistic regressions for binary variables (at least one such day).

\section{Sensitivity analyses}

To test for the robustness of our results, we ran one-way sensitivity analyses and varied the following assumptions: human capital approach instead of frictional cost to assess costs due to absenteeism (main calculations); only complete responses compared to complete \& imputed responses (main calculations); and uniform annual inflation rates (0 \% vs. $5 \%$ ) [56] compared to the sectorand year-specific rates (main calculations).

\section{Additional analyses}

To examine the impact of AD characteristics on the economic burden, we performed additional analyses. For both CIDI and GP diagnoses, costs were estimated separately and compared to the remaining sample without the respective diagnosis using negative binomial regressions adjusting for age and sex. Direct comparisons were not immediately feasible as GP and CIDI diagnoses did not result in two entirely distinct but in two slightly overlapping groups [7]. As indicators for AD severity, we referred to professional treatment (AD severity I; combined assessment by GP and patient), as well as number of DSM-5 AUD criteria (AD severity II; assessed by CIDI) and daily drinking levels (AD severity III; assessed by CIDI). For AD severity I, we examined excess costs associated with treatment for $\mathrm{AD}$ among all diagnosed patients using a binary indicator. For AD severity II and III, separate models examined the association of each continuous predictor with the respective costs among all patients. For the latter models, direct (excess) cost estimations for separate groups were not feasible as they did not imply distinct groups for which costs could be estimated for. All associations with individual costs and the respective $\mathrm{AD}$ characteristics were determined with age and sex adjusted negative binomial regressions for direct, indirect and overall costs.

\section{Results \\ Sociodemographics}

A detailed description of the entire APC sample can be found in previous publications (Additional file 2 of $[32,57])$. For the German sample $(N=1,356)$, Table 1 presents sociodemographics by AD diagnosis. Mean patient age was 45 years and $56.9 \%$ were female. AD diagnoses by GP or CIDI were given to $17.0 \%$ and $6.4 \%$ of all male and female primary care patients, respectively (total: $11.0 \%$ ). Among patients with $\mathrm{AD}$ diagnoses, males and patients who rated their socioeconomic status above average were overrepresented, while an average 
Table 1 Sociodemographics and disability by AD diagnosis

\begin{tabular}{|c|c|c|c|c|}
\hline & All patients & Non-AD & $A D$ & $p^{a}$ \\
\hline & $N=1,356$ & $N=1,213$ & $N=143$ & \\
\hline Sex (\% female, Cl) & $56.9(54.2-59.5)$ & $59.8(57.1-62.6)$ & $33.0(25.3-40.7)$ & $<.001$ \\
\hline \multicolumn{5}{|l|}{ Age $(\%, C l)$} \\
\hline $18-29$ & $19.6(17.5-21.7)$ & $19.1(16.9-21.3)$ & $23.4(16.5-30.3)$ & .218 \\
\hline $30-39$ & $17.9(15.9-20.0)$ & $17.9(15.7-20.1)$ & $18.3(12.0-24.6)$ & .908 \\
\hline $40-49$ & $18.7(16.6-20.8)$ & $19.1(16.9-21.4)$ & $14.8(9.0-20.7)$ & .218 \\
\hline $50-64$ & $43.8(41.2-46.5)$ & $43.9(41.0-46.7)$ & $43.5(35.3-51.7)$ & .930 \\
\hline Unemployment (\%, Cl) & $12.4(10.6-14.1)$ & $11.8(9.9-13.6)$ & $17.0(10.8-23.2)$ & .078 \\
\hline \multicolumn{5}{|l|}{ Socioeconomic status $(\%, \mathrm{Cl})$} \\
\hline Above average & $20.1(18.0-22.3)$ & $19.3(17.1-21.6)$ & $26.8(19.5-34.1)$ & .037 \\
\hline Average & $69.0(66.5-71.5)$ & $70.0(67.5-72.6)$ & $60.5(52.5-68.6)$ & .021 \\
\hline Below average & $10.9(9.2-12.5)$ & $10.6(8.9-12.4)$ & $12.7(7.2-18.2)$ & .459 \\
\hline Disability score (WHODAS, mean, SD) & $14.8(14.7)$ & $14.4(14.4)$ & $18.1(16.2)$ & .004 \\
\hline
\end{tabular}

Note

AD Alcohol dependence, Cl 95 \% confidence interval, WHODAS World Health Organization Disability Assessment Schedule 2.0

a difference between $A D$ and non-AD cases was determined using Chi $^{2}$-Tests (F-distribution) for binary variables (sex, age categories, unemployment, socioeconomic categories) and negative binomial regression for the count variable (WHODAS sum score)

socioeconomic status was less common in this group. Further, AD cases showed higher disability levels as compared to the remaining sample. No statistically significant differences could be found for the distribution of age and unemployment.

\section{Resource use data}

Resource use data were collected from the German APC study for six months before the time of interview. Descriptive summary statistics of these data by AD and sex can be found in Table 2. Among patients without AD diagnosis, three patients $(0.2 \%)$ reported treatment for alcohol problems, as compared to ten patients $(7 \%)$ in the AD group.

\section{Economic burden associated with AD}

All presented costs represent the results from combining collected resource use data from the German APC study (Table 2) with German unit costs (Additional file 2). Table 3 presents the direct and indirect costs by spending sector, $\mathrm{AD}$ and sex. Across all patients, we have estimated that $3879.66 €$ of direct and indirect costs incurred per patient. Of all costs calculated for the entire sample (5405230.60€), $15 \%$ incurred among patients with an AD diagnosis (811767.45€). The economic burden associated with $\mathrm{AD}$ was determined through the mean cost difference between patients with and without an $\mathrm{AD}$ diagnosis and equalled $1836.35 €$ per $\mathrm{AD}$ case $(p$ $<.001$; age adjusted). In comparison to direct costs, productivity loss made up the larger share of this burden (57\% of all costs). The three largest components of the economic burden were disability/early retirement (27\%), inpatient treatment (26\%) and unemployment (20\%), which represented almost $75 \%$ of the entire economic burden associated with AD. Alcohol treatment constituted only about $6 \%$ of this burden.

\section{Sex- and age-stratified analyses}

Sex-stratified analyses for both male and female AD patients found significant excess costs, too. Adding sex as further covariate to the age-adjusted main model (see Table 3) predicting total costs by AD diagnosis produced a non-significant effect of $\operatorname{sex}(p=.558$; other results not shown). Fig. 1 illustrates total costs per patient by AD diagnosis for consecutive age groups, with excess costs amounting to $889.48 €(p=.099 ; 18-29$ year old $)$, $4211.53 €(p<.001 ; 30-39$ year old $), 3850.06 €(p=.006$; $40-49$ year old), $775.86 €(p=.373 ; 50-59$ year old), and $715.26 €(p=.269 ; 60-64$ year old $)$.

\section{Direct costs}

We found higher direct costs due to health care utilization among AD cases irrespective of including or excluding alcohol treatment. Overall, $18 \%$ of all direct costs incurred among patients with an AD diagnosis. Inpatient treatment - not including specialized alcoholrelated hospitalization - produced the highest share of mean direct excess costs $(468.85 €)$, followed by GP treatment (120.34€) and alcohol-specific treatment (104.87€).

According to the results from the zero-inflated model, excess costs in inpatient admissions were likely to be due to a greater proportion of male AD cases reporting any inpatient admission (logit model), while differences in the costs of admissions were not found (count 
Table 2 Resource use data in six months before interview by alcohol dependence and sex

\begin{tabular}{|c|c|c|c|c|c|c|c|}
\hline & \multirow{3}{*}{$\begin{array}{l}\text { All patients } \\
N=1356\end{array}$} & \multicolumn{3}{|l|}{ Non-AD } & \multicolumn{3}{|l|}{$A D$} \\
\hline & & male & female & total & male & female & total \\
\hline & & $N=494$ & $N=719$ & $N=1213$ & $N=95$ & $N=48$ & $N=143$ \\
\hline \multicolumn{8}{|l|}{ Direct costs } \\
\hline $\begin{array}{l}\text { Inpatient admissions }{ }^{a} \\
\text { Number of nights, mean (SD) }\end{array}$ & $1.2(5.2)$ & $1.2(6.0)$ & $1.1(4.1)$ & $1.2(5.0)$ & $2.5(7.3)$ & $0.9(3.4)$ & $2.0(6.4)$ \\
\hline $\begin{array}{l}\text { Outpatient visits }{ }^{a} \\
\text { At least one visit, \% (Cl) }\end{array}$ & $9.9(8.3-11.6)$ & $8.7(6.2-11.2)$ & $9.9(7.7-12.1)$ & $9.4(7.8-11.1)$ & $15.8(8.2-23.4)$ & $10.1(1.7-18.5)$ & $13.9(8.1-19.7)$ \\
\hline $\begin{array}{l}\text { Day case surgery visits }{ }^{a} \\
\text { At least one visit, } \%(C l)\end{array}$ & $6.0(4.7-7.3)$ & $4.9(3.0-6.8)$ & $6.0(4.3-7.9)$ & $5.6(4.3-6.9)$ & $10.1(3.8-16.4)$ & $8.2(0.5-16.0)$ & $9.5(4.6-14.4)$ \\
\hline $\begin{array}{l}\text { Accident \& emergency visits }{ }^{a} \\
\text { At least one visit, } \%(C l)\end{array}$ & $11.2(9.5-12.9)$ & $8.7(6.2-11.2)$ & $10.7(8.4-13.0)$ & $9.9(8.2-11.6)$ & $22.0(13.5-30.5)$ & $21.7(9.8-33.6)$ & 21.9 (15.0-28.8) \\
\hline $\begin{array}{l}\text { GP treatment }{ }^{a} \\
\text { Number of visits, mean (SD) }\end{array}$ & $6.8(11.4)$ & $5.8(9.9)$ & $6.8(6.4)$ & $6.4(8.0)$ & $10.4(25.6)$ & $9.6(24.0)$ & $10.2(25.1)$ \\
\hline $\begin{array}{l}\text { Prescribed medication }{ }^{\text {a }} \\
\text { Number of prescriptions, } \\
\text { mean (SD) }\end{array}$ & $1.8(1.5)$ & $1.8(1.5)$ & $1.9(1.5)$ & $1.8(1.5)$ & $2.1(1.5)$ & $1.7(1.4)$ & $1.9(1.5)$ \\
\hline $\begin{array}{l}\text { Home care }^{\text {a }} \\
\text { At least one home visit, \% (Cl) }\end{array}$ & $5.2(4.0-6.4)$ & $5.1(3.1-7.1)$ & $5.1(3.5-6.8)$ & $5.8(3.9-6.4)$ & $7.6(2.2-13.1)$ & $2.2(0.0-6.4)$ & $5.8(1.9-9.8)$ \\
\hline $\begin{array}{l}\text { Alcohol treatment } \\
\text { At least one treatment } \\
\text { contact, \% (Cl) }\end{array}$ & $1.0(0.5-1.5)$ & $0.4(0.0-0.9)$ & $0.1(0.0-0.4)$ & $0.2(0.0-0.5)$ & $9.6(3.6-15.5)$ & $2.3(0.0-6.6)$ & $7.2(2.9-11.4)$ \\
\hline \multicolumn{8}{|l|}{ Indirect costs } \\
\hline $\begin{array}{l}\text { Absenteeism among } \\
\text { employed patients } \\
\text { Number of absent days, } \\
\text { mean (SD) }\end{array}$ & $8.1(20.4)$ & $5.5(15.4)$ & $8.7(18.4)$ & $7.3(17.2)$ & $17.2(41.1)$ & 12.9 (26.6) & 16.1 (37.9) \\
\hline $\begin{array}{l}\text { Unemployment } \\
\%(\mathrm{Cl})\end{array}$ & $8.2(6.7-9.7)$ & $7.7(5.3-10.0)$ & 7.8 (5.8-9.8) & $7.8(6.2-9.3)$ & $10.5(4.3-16.7)$ & $13.9(4.3-23.6)$ & $11.7(6.4-16.9)$ \\
\hline $\begin{array}{l}\text { Disability/early retirement } \\
\%(\mathrm{Cl})\end{array}$ & $16.5(14.5-18.5)$ & $17.6(14.2-21.0)$ & $14.7(12.1-17.3)$ & $15.8(13.8-17.9)$ & $22.2(13.6-30.7)$ & $21.6(9.8-33.5)$ & $22.0(15.0-28.9)$ \\
\hline
\end{tabular}

model). For home care related costs (excess costs per male AD case: $85.08 €$ ), the results were the other way round, with male $\mathrm{AD}$ patients being just as likely to report any home care (logit model), but if they received any home care, their costs were higher (count model) than those of other male patients.

Results of direct mean cost differences among female patients with or without an AD diagnosis were quite mixed and not significant in most sectors, except for reception of home care services. Only one female AD case reported receiving some kind of home care, thus resulting in significant lower costs compared to other female patients $(-23.05 €$ per female $\mathrm{AD}$ case). Alcohol treatment was found to make up the largest share of excess costs among female AD cases (261.08€ per case), but this was mainly due to a single case reporting 40 inpatient nights which resulted in a large mean and standard deviation. Overall, the excess direct costs associated with $\mathrm{AD}$ equalled $230.78 €$ per female patient but were not significantly different from zero.

\section{Indirect costs}

Indirect costs due to absenteeism, unemployment and disability or early retirement were found to be concentrated among $\mathrm{AD}$ cases, which were responsible for $14 \%$ of all indirect costs. On average, these costs were 1,050.97€ higher among $\mathrm{AD}$ cases as compared to other patients. This finding was also reproduced in sex-stratified analyses but not for all components of indirect costs. In total, indirect costs account for more than half of all observed excess costs, which is also demonstrated by Fig. 2 .

We found that presenteeism was also more prevalent among AD cases (see Table 4). Male patients with an $\mathrm{AD}$ diagnosis reported more days with reduced work capacity due to any health condition (WHODAS 2.0) or due to mental distress (K10) as compared to non-AD cases. Further, for both male and female patients, alcohol-associated work impairment was present. While about $4 \%$ of all cases with a gainful occupation perceived their productivity to be affected by their drinking, this rate was significantly higher among $\mathrm{AD}$ cases $(22 \%)$. 
Table 3 Average direct and indirect costs per patient in six months before interview in 2014-€

\begin{tabular}{|c|c|c|c|c|c|c|c|c|c|c|}
\hline & \multirow{3}{*}{$\begin{array}{l}\text { All patients } \\
N=1356\end{array}$} & \multicolumn{3}{|l|}{ Non-AD } & \multicolumn{3}{|l|}{$A D$} & \multicolumn{3}{|l|}{ Excess costs } \\
\hline & & male & female & total & male & female & total & male & female & total \\
\hline & & $N=494$ & $N=719$ & $N=1213$ & $N=95$ & $N=48$ & $N=143$ & $N=589$ & $N=767$ & $N=1356$ \\
\hline \multicolumn{11}{|l|}{ Direct costs } \\
\hline $\begin{array}{l}\text { Inpatient } \\
\text { admissions }^{1 a}\end{array}$ & $605.53(2446.48)$ & $569.42(2766.16)$ & 543.82 (1997.69) & $554.10(2332.50)$ & 1300.61 (3650.39) & 458.99 (1634.33) & $1022.95(3165.99)$ & $731.18^{\circ 0-}$ & -84.80 & $468.85^{\circ-}$ \\
\hline Outpatient visits ${ }^{1 a}$ & $9.78(26.73)$ & 8.96 (29.28) & $9.08(20.96)$ & $9.03(24.59)$ & $17.03(45.01)$ & $13.50(21.81)$ & $15.86(39.06)$ & $8.07^{\circ-}$ & 4.41 & $6.83^{\circ-}$ \\
\hline GP treatment ${ }^{2 a}$ & $219.41(361.28)$ & $189.23(321.42)$ & 217.60 (205.77) & $206.22(326.56)$ & $336.03(800.45)$ & 307.33 (749.01) & $326.56(784.31)$ & $146.81^{*+}$ & 89.73 & $120.34^{*+}$ \\
\hline $\begin{array}{l}\text { Prescribed } \\
\text { medication }^{1 a}\end{array}$ & $143.45(424.96)$ & $157.10(521.57)$ & $128.18(344.64)$ & $139.79(423.90)$ & $203.94(511.76)$ & $110.77(152.41)$ & 173.21 (431.74) & 46.84 & -17.41 & 33.41 \\
\hline Home care ${ }^{1 a}$ & 26.69 (226.05) & 17.72 (121.62) & 23.98 (148.22) & 21.47 (138.34) & $102.80(661.66)$ & $0.93(6.14)$ & $69.19(546.01)$ & $85.08^{*^{+}}$ & $-23.05^{* * *^{-}}$ & 47.73 \\
\hline Alcohol treatment ${ }^{1}$ & $11.63(331.60)$ & $0.36(8.27)$ & $0.0(0.0)^{d}$ & $0.14(5.21)$ & 28.18 (115.97) & 261.08 (1699.39) & $105.01(978.30)$ & $27.82^{000-}$ & $261.08^{b}$ & $104.87 * * *+\infty 00-$ \\
\hline $\begin{array}{l}\text { Total direct costs } \\
\text { excluding alcohol } \\
\text { treatment }^{2}\end{array}$ & $1003.68(2609.80)$ & 940.67 (2931.95) & 921.81 (2131.66) & 929.38 (2479.83) & 1960.41 (3871.48) & 891.52 (1913.02) & $1607.77(3400.08)$ & $1019.744^{* *^{+}}$ & -30.29 & $678.39 * *^{*+}$ \\
\hline $\begin{array}{l}\text { Total direct costs } \\
\text { including alcohol } \\
\text { treatment }{ }^{2}\end{array}$ & $1015.31(2628.83)$ & $941.03(2931.86)$ & $921.81(2131.66)$ & 929.53 (2479.79) & 1988.59 (3869.34) & 1152.59 (2507.64) & $1712.79(3508.16)$ & $1047.56 * * *+$ & 230.78 & $783.26^{* * *+}$ \\
\hline \multicolumn{11}{|l|}{ Indirect costs } \\
\hline $\begin{array}{l}\text { Absenteeism } \\
\text { among employed } \\
\text { patients }{ }^{1 c}\end{array}$ & $680.11(1734.23)$ & 584.05 (1542.06) & 711.72 (1742.10) & $660.41(1667.00)$ & $932.67(2377.10)$ & $652.28(1684.31)$ & 840.17 (2180.79) & $348.62 *^{*+}$ & -59.44 & $179.76^{*^{+}}$ \\
\hline Unemployment ${ }^{3}$ & $784.20(2626.86)$ & 732.85 (2570.54) & 750.31 (2568.01) & 743.29 (2569.20) & $1008.96(2873.82)$ & $1335.22(3284.69)$ & $1116.60(3017.16)$ & 276.12 & 584.91 & 373.31 \\
\hline $\begin{array}{l}\text { Disability/early } \\
\text { retirement }^{3}\end{array}$ & $1402.00(3156.06)$ & $1445.88(3161.93)$ & $1281.27(3084.52)$ & $1347.43(3116.68)$ & $1824.21(3340.81)$ & 1888.23 (3561.13) & $1845.33(3414.18)$ & 378.34 & 606.96 & $497.90^{*+}$ \\
\hline $\begin{array}{l}\text { Total indirect } \\
\text { costs } 1\end{array}$ & 2866.31 (3833.04) & 2762.78 (3772.04) & $2743.30(3788.09)$ & $2751.13(3782.01)$ & $3765.85(4062.60)$ & $3875.72(4152.24)$ & $3802.10(4092.50)$ & $1003.07^{* *+}$ & $1132.42^{*+}$ & $1050.97^{* * *+}$ \\
\hline \multicolumn{11}{|l|}{ Total costs } \\
\hline $\begin{array}{l}\text { Total costs } \\
\text { excluding alcohol } \\
\text { treatment }{ }^{2}\end{array}$ & 3868.03 (5092.91) & $3703.45(5133.10)$ & $3661.58(4755.51)$ & 3678.39 (4908.87) & $5726.26(6590.02)$ & $4767.24(5004.35)$ & $5409.87(6137.53)$ & $2058.366^{*+}$ & $1105.66^{* *+}$ & $1731.48 * * *^{+}$ \\
\hline $\begin{array}{l}\text { Total costs } \\
\text { including alcohol } \\
\text { treatment }{ }^{2}\end{array}$ & 3879.66 (5114.32) & 3703.81 (5133.53) & 3661.58 (4755.51) & 3678.54 (4909.05) & $5754.44(6591.28)$ & $5028.32(5491.93)$ & $5514.89(6265.50)$ & $2050.64^{* *^{+}}$ & $1366.74^{* *^{+}}$ & $1836.35^{* * *^{+}}$ \\
\hline
\end{tabular}

Note. All presented costs refer to reported and imputed costs and are presented as mean cost per patient with standard deviation in brackets

Significance of excess costs was tested with ${ }^{1}$ zero-inflated negative binomial regressions or ${ }^{2}$ negative binomial regressions, using alcohol dependence and age as predictors in both count (predicting values $>0$ ) and logit (predicting 0 , only for zero-inflated negative binomial regressions) model. The following symbols indicate a significant $\operatorname{AD}$ predictor: count model ${ }^{*} p<.05 * * p<.01 * * * p<.001$; logit model + or - behind the symbol indicates valence of respective coefficient

${ }^{3}$ significance of excess costs was tested with age-adjusted logistic regressions for unemployment and disability (collapsing sex-specific costs into a single value). The same legend for $p$-values applies as for negative binomial models 
$A D$ Alcohol dependence, GP General practitioner

a excluding all alcohol-specific treatments (medication, inpatient and outpatient treatment, group therapy, (GP) counselling/detoxification)

$\mathrm{b}$ only one case with alcohol related treatment costs among female AD patients: $x^{2}$-test on contingency table with one cell having 0 counts (female non-AD patients), one cell 1 count (female AD patients): $p<.001$

c costs of absenteeism according to friction cost method

d no costs despite resource use because one "other alcohol contact" was specified but as the type of contact was not specified, this contact was not included in the cost calculation 
$\square$ Patients without alcohol dependence

$\square$ Patients with alcohol dependence
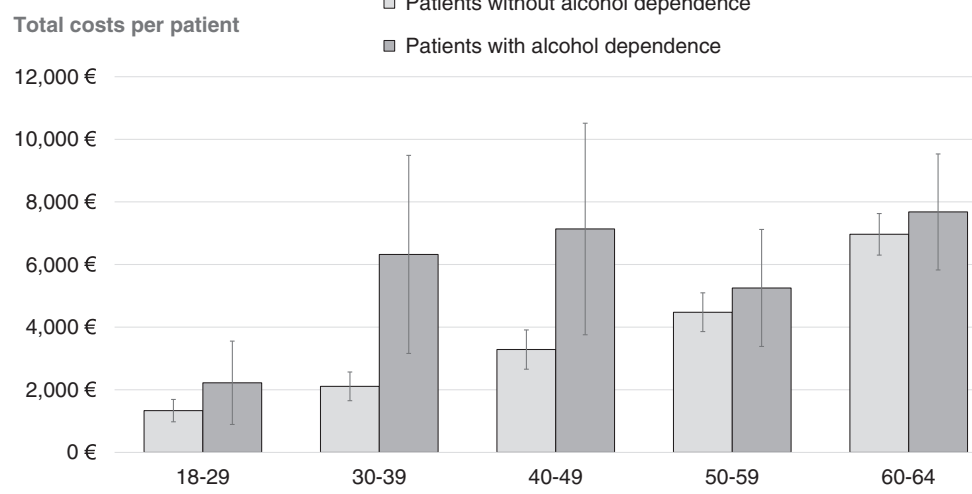

Age in years

Fig. 1 Total costs per patient by age and AD diagnosis

\section{Sensitivity analysis}

A one-way sensitivity analysis was conducted, varying assumptions on costs due to absenteeism, imputation of missing values, and annual inflation rates (see Table 5). Results suggest that extent and significance of mean excess costs among AD cases remained significant under all observed conditions.

Using the human capital approach yielded expectedly higher indirect costs via absenteeism, with total costs being $8.6 \%$ greater following this approach as compared to the frictional cost approach. Excluding all imputed values from cost estimations produced small changes in direct costs $(-6.4 \%)$ and total costs $(-1.6 \%)$. Compared to sector- and year-specific inflation rates (main calculations), estimating the economic burden assuming $0 \%$ or $5 \%$ inflation led to a $4.1 \%$ decrease and a $5.5 \%$ increase, respectively.

\section{Additional analysis}

Results from additional analyses examining the impact of the diagnostic approach (GP vs. CIDI) and of different AD severity indicators are presented in Table 6. A significant economic burden was observed regardless of the diagnostic approach, with significantly higher indirect costs associated with both diagnoses. Direct costs were found to be significantly higher among GP diagnosed patients but not among CIDI diagnosed patients.

Results of the association of various AD severity indicators and incurred costs were mixed. For AD severity I, costs were not significantly different between treated and untreated AD cases. Similarly, no significant association between daily drinking levels (AD severity III) and individual costs was observed for any of the examined cost domains. However, the only significant association was established for the number of AUD criteria (AD severity II) and indirect as well as total costs: The more AUD criteria were met, the higher costs incurred.

\section{Discussion}

Summary

This study sought to estimate the economic burden associated with AD using a bottom-up approach with a sample of 1356 German primary care patients. Our estimations considered direct and indirect costs separately

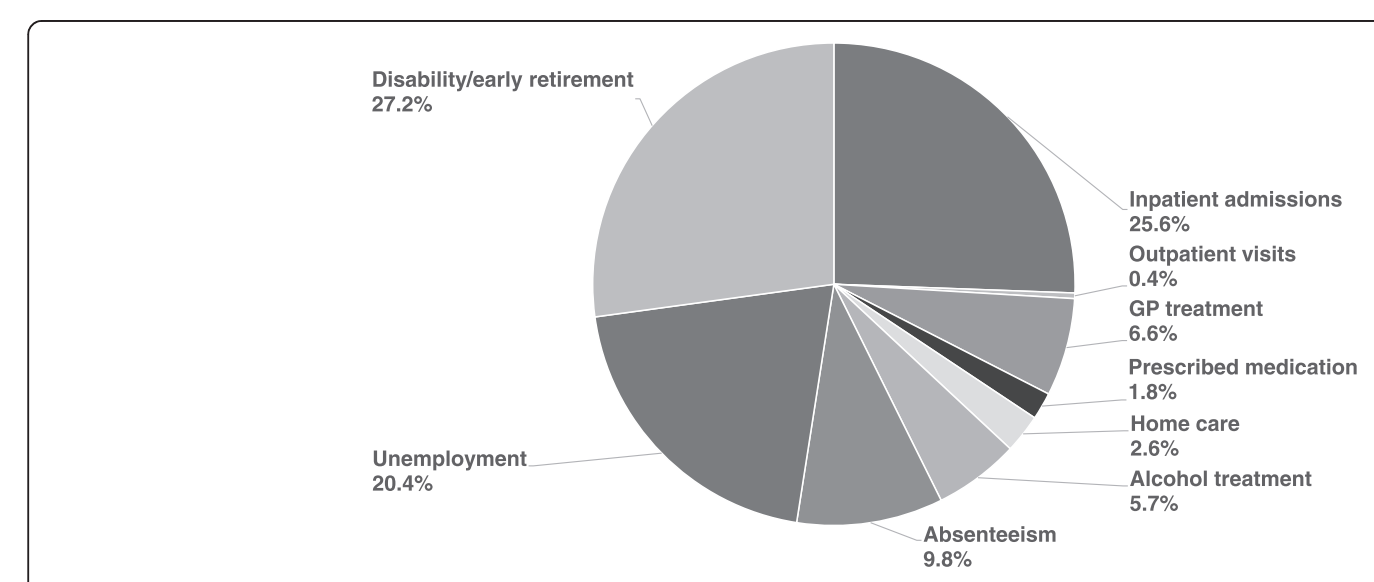

Fig. 2 Share of excess costs of alcohol dependence by sector 
and additional analyses examined the impact of several $\mathrm{AD}$ characteristics on respective costs.

In the sample studied, the economic burden of $\mathrm{AD}$ was determined using excess costs which amounted to about $1867 €$ per case. In other words, the direct and indirect costs among $\mathrm{AD}$ patients were about $50 \%$ higher compared to primary care patients without AD. Ageand sex-stratified analyses showed that these costs were concentrated among males and patients aged 30 to 50 . Excess costs were largely attributable to indirect costs (57\%) in addition to costs related to inpatient treatment (25\%). Costs reported for different kinds of alcohol treatment made up a relatively small share, amounting to $6 \%$ of the excess costs. Sensitivity analysis suggests that the estimates are robust under various assumptions.

Additional analyses indicate that increased costs were independent of the approach to diagnose $\mathrm{AD}$, as overall costs were significantly higher among both GP and CIDI diagnosed primary care patients, as compared to nonAD cases. Furthermore, our results suggest that costs may increase with AD severity but this finding was limited to the number of AUD criteria and could not be reproduced with treatment of $\mathrm{AD}$ and drinking levels.

\section{Comparison with top-down estimations}

In comparison with previous top-down estimations, the costs per patient and the breakup of direct and indirect costs were very similar $[11,12,21]$, which supports the validity of studies using top-down methods. A more detailed look at the results reveals that indirect costs were consistently found to account for the majority of all costs, in this sample (57\%), in a German study on alcohol-associated costs (65 \%) [12], and in a systematic review on $\mathrm{AD}$-associated economic burden in highincome countries (72 \%) [11]. However, top-down estimations usually included costs due to premature mortality in their estimations, e.g. being accountable for $45 \%$ of all alcohol-associated costs in the above-mentioned German study. If we adjusted indirect cost estimations in the other studies to the same definition as used in our study by excluding premature mortality, the share of indirect costs would be reduced markedly to only $20 \%$ in the German study and to $52 \%$ across various highincome countries. Thus, the reported indirect costs in our sample were comparably high, especially compared to the German study. This discrepancy may be explained by differences between this sample and general population studies, with primary care patients being older and having more mental and physical health issues, which is related to unemployment and claims of disability benefits or early retirement pensions [58, 59]. Further, to grant any sick leave in Germany, employers commonly ask their employees to provide certification of illness from a medical professional, linking absenteeism closely to GP visits.

\section{Implications}

Our results suggest that the overwhelming majority of the economic burden was not due to the direct treatment of AD but more than $80 \%$ was attributable to paid absence from work, disability or early retirement, and inpatient treatment of comorbid health problems. Given the low treatment rates for $\mathrm{AD}(17.2 \%$ in this sample, see [57]) and a non-significant impact of AD treatment

Table 4 Descriptive measures of presenteeism among gainfully occupied patients

\begin{tabular}{|c|c|c|c|c|c|c|c|}
\hline & \multirow{3}{*}{$\begin{array}{l}\text { All patients } \\
N=792\end{array}$} & \multicolumn{3}{|l|}{ Non-AD } & \multicolumn{3}{|l|}{$A D$} \\
\hline & & male & female & total & male & female & total \\
\hline & & $N=317$ & $N=403$ & $N=720$ & $N=52$ & $N=20$ & $N=72$ \\
\hline $\begin{array}{l}\text { Number of days of reduced } \\
\text { work in past } 30 \text { days due to any } \\
\text { health condition (WHODAS } \\
2.0 \mathrm{H3} \text { ), mean (SD) }\end{array}$ & $3.0(6.1)$ & $2.3(5.1)$ & $3.3(6.2)$ & $2.9(5.8)$ & $4.0(8.2) *^{*+}$ & $3.6(7.5)$ & $3.9(8.0) *+$ \\
\hline $\begin{array}{l}\text { Number of days with at most } \\
\text { half of usual work capacity in } \\
\text { past } 30 \text { days due to mental } \\
\text { distress (K10 Q6), mean (SD) }\end{array}$ & $2.0(4.4)$ & $1.4(3.2)$ & $2.1(4.1)$ & $1.7(3.8)$ & $3.2(7.2)^{* *+}$ & $6.7(8.7)$ & $4.1(7.7) * * *+$ \\
\hline \multicolumn{8}{|c|}{ Impaired work productivity due to drinking in past six months } \\
\hline $\begin{array}{l}\text { At least one day, proportion } \\
(95 \% \mathrm{Cl})\end{array}$ & $3.8(2.5-5.2)$ & $4.2(2.0-6.5)$ & $0.3(0.0-0.8)$ & $2.0(1.0-3.0)$ & $24.1(12.2-35.9) * * *+$ & $16.0(0.0-32.7) *^{*+}$ & $21.9(12.1-31.7) * * *+$ \\
\hline Number of days, mean (SD) & $0.3(3.1)$ & $0.1(0.8)$ & $0.0(0.1)$ & $0.1(0.5)$ & $2.9(10.8) * *+$ & $0.4(1.2)^{\circ-}$ & $2.3(9.4) * *+o-$ \\
\hline
\end{tabular}

Significance between patients with and without AD was tested with zero-inflated negative binomial regressions for all count variables, using alcohol dependence and age as predictor in both count (predicting values $>0$ ) and logit (predicting 0 ) model. The following symbols indicate a significant $A D$ predictor: count model * $p<.05^{* *} p<.01{ }^{* * *} p<.001$; logit model ${ }^{\circ} p<.05^{\circ 0} p<.01+$ or - behind the symbol indicates valence of respective coefficient

For the binary variable indicating at least one day with impaired productivity due to drinking, an age-adjusted logistic regression was conducted. The same legend for $\mathrm{p}$-values also applies to negative binomial models

AD Alcohol dependence, WHODAS World Health Organization Disability Assessment Schedule 2.0, SD Standard deviation, K10 Kessler Psychological Distress Scale, $95 \%$ Cl $95 \%$ confidence interval 
Table 5 One-way sensitivity analyses: variation of assumptions on costs of productivity, imputed values, and inflation rates

\begin{tabular}{|c|c|c|c|c|c|c|c|c|c|c|c|c|}
\hline & \multicolumn{3}{|c|}{ Human capital approach } & \multicolumn{3}{|c|}{ Only unimputed costs } & \multicolumn{3}{|c|}{ Annual inflation rate $0 \%$} & \multicolumn{3}{|c|}{ Annual inflation rate $5 \%$} \\
\hline & Non-AD & $A D$ & Total & Non-AD & $A D$ & Total & Non-AD & $A D$ & Total & Non-AD & $A D$ & Total \\
\hline & $\begin{array}{l}N= \\
1,213\end{array}$ & $N=143$ & $\begin{array}{l}N= \\
1,356\end{array}$ & $\begin{array}{l}N= \\
1,213\end{array}$ & $N=143$ & $N=1,356$ & $N=1,213$ & $N=143$ & $N=1,356$ & $N=1,213$ & $N=143$ & $\begin{array}{l}N= \\
1,356\end{array}$ \\
\hline \multicolumn{13}{|l|}{ Direct costs } \\
\hline $\begin{array}{l}\text { Total direct } \\
\text { costs } \\
\text { excluding } \\
\text { alcohol } \\
\text { treatment }\end{array}$ & / & / & / & $\begin{array}{c}867.28 \\
(2466.25)\end{array}$ & $1559.27(3405.17)^{* *+}$ & 943.07 (2599.48) & $800.91(1950.23)$ & $1371.41(2715.12){ }^{* *+}$ & $863.40(2059.54)$ & $1171.80(3393.09)$ & $2035.01(4551.12)^{* *+}$ & $\begin{array}{l}1266.34 \\
(3554.46)\end{array}$ \\
\hline $\begin{array}{l}\text { Total direct } \\
\text { costs } \\
\text { including } \\
\text { alcohol } \\
\text { treatment }^{1}\end{array}$ & / & / & / & $\begin{array}{l}867.42 \\
(2466.21)\end{array}$ & $\underset{* * * *+}{1659.84}(3511.19)$ & $954.21(2618.22)$ & 801.06 (1950.18) & $\begin{array}{l}1476.12(2857.76) \\
* * *+\end{array}$ & $875.00(2084.39)$ & $1171.96(3393.04)$ & $\underset{* * *+}{2141.91}(4624.28)$ & $\begin{array}{l}1278.19 \\
(3567.83)\end{array}$ \\
\hline \multicolumn{13}{|l|}{ Indirect costs } \\
\hline Absenteeism ${ }^{2}$ & $\begin{array}{l}941.91 \\
(3004.53)\end{array}$ & $\begin{array}{l}1893.80 \\
(6667.85) \\
* *+\end{array}$ & $\begin{array}{l}1046.24 \\
(3626.33)\end{array}$ & / & / & / & $654.52(1652.13)$ & $\begin{array}{l}832.67(2161.33) \\
*+\end{array}$ & $674.04(1718.76)$ & $687.24(1734.74)$ & $874.31(2269.40)^{*+}$ & $\begin{array}{l}707.74 \\
(1804.70)\end{array}$ \\
\hline $\begin{array}{l}\text { Total indirect } \\
\text { costs }^{2}\end{array}$ & $\begin{array}{l}3032.64 \\
(4400.97)\end{array}$ & $\begin{array}{l}4855.73 \\
(7102.00) \\
* * * *^{+}\end{array}$ & $\begin{array}{l}3232.44 \\
(4820.05)\end{array}$ & ' & / & / & $\begin{array}{l}2738.60 \\
(3766.75)\end{array}$ & $\begin{array}{l}3784.64(4073.89) \\
* * *+\end{array}$ & $\begin{array}{l}2853.25 \\
(3817.31)\end{array}$ & $2808.17(3852.92)$ & $\underset{* * *+}{3881.61}(4179.12)$ & $\begin{array}{l}2925.82 \\
(3906.19)\end{array}$ \\
\hline \multicolumn{13}{|l|}{ Total costs } \\
\hline $\begin{array}{l}\text { Total costs } \\
\text { excluding } \\
\text { alcohol } \\
\text { treatment }{ }^{1}\end{array}$ & $\begin{array}{l}3959.68 \\
(5504.37)\end{array}$ & $\begin{array}{l}6463.50 \\
(9368.64) \\
* * *+\end{array}$ & $\begin{array}{l}4233.91 \\
(6119.86)\end{array}$ & $\begin{array}{l}3616.29 \\
(4889.88)\end{array}$ & $\underset{* * *+}{5361.37}(6139.02)$ & $\begin{array}{l}3807.41 \\
(5077.34)\end{array}$ & $\begin{array}{l}3537.41 \\
(4582.74)\end{array}$ & $\begin{array}{l}5156.05 \\
* * *^{+}\end{array}$ & $\begin{array}{l}3714.69 \\
(4740.96)\end{array}$ & $3977.80(5583.99)$ & $\begin{array}{l}5916.62(7106.93) \\
* * *^{+}\end{array}$ & $\begin{array}{l}4190.15 \\
(5809.62)\end{array}$ \\
\hline $\begin{array}{l}\text { Total costs } \\
\text { including } \\
\text { alcohol } \\
\text { treatment }{ }^{1}\end{array}$ & $\begin{array}{l}3959.83 \\
(5504.52)\end{array}$ & $\begin{array}{l}6568.52 \\
(9442.82) \\
* * *^{+}\end{array}$ & $\begin{array}{l}4245.54 \\
(6137.20)\end{array}$ & $\begin{array}{l}3616.43 \\
(4890.06)\end{array}$ & ${ }_{* * *+}^{5461.94}(6268.48)$ & $\begin{array}{l}3818.56 \\
(5098.91)\end{array}$ & $\begin{array}{l}3537.56 \\
(4582.94)\end{array}$ & $\begin{array}{l}5260.77(5772.92) \\
* * *+\end{array}$ & $\begin{array}{l}3726.29 \\
(4764.30)\end{array}$ & $3977.96(5584.17)$ & $\underset{* * *+}{6023.52}(7212.45)$ & $\begin{array}{l}4202.00 \\
(5828.11)\end{array}$ \\
\hline
\end{tabular}

Note. All presented costs refer to mean cost per patient with standard deviation in brackets

Imputations mainly affect the prescribed medication section, in addition to inpatient treatment, home care, and alcohol treatment

Significance of excess costs was tested with ${ }^{1}$ negative binomial regressions or ${ }^{2}$ zero-inflated negative binomial regressions using alcohol dependence and age as predictors in both count (predicting values $>0$ ) and logit (predicting 0 , only for zero-inflated negative binomial regressions) model. The following symbols indicate a significant AD predictor: count model ${ }^{*} p<.05 * * p<.01 * * * p<.001 ;$ logit model ${ }^{\circ} p<.05{ }^{\circ 0} p<.01{ }^{\circ 00} p$ $<.001$. + or - behind the symbol indicates valence of respective coefficient

$A D$ Alcohol dependence. / = same value as in Table 1, i.e. not affected by human capital approach or by imputations 
Table 6 Association of AD characteristics and individual costs

\begin{tabular}{|c|c|c|c|c|c|}
\hline & \multicolumn{2}{|l|}{ Type of AD diagnosis ${ }^{a}$} & \multirow{2}{*}{$\begin{array}{l}A D \text { severity } I^{b} \\
\text { Excess costs: } A D \text { treatment }\end{array}$} & \multirow{2}{*}{$\begin{array}{l}\text { AD severity II }{ }^{c} \\
\text { IRR: DSM-5 AUD } \\
\text { criteria }\end{array}$} & \multirow{2}{*}{$\begin{array}{l}\text { AD severity III }{ }^{\mathrm{C}} \\
\text { IRR: Daily drinking } \\
\text { levels }\end{array}$} \\
\hline & Excess costs: GP AD & Excess costs: CIDI AD & & & \\
\hline & $N=1,356$ & $N=1,356$ & $N=143$ & $N=1,356$ & $N=1,356$ \\
\hline $\begin{array}{l}\text { All direct costs } \\
(95 \% \mathrm{Cl})\end{array}$ & $1132.20(198.64-2066.09)^{* *}$ & $322.07(-303.93-948.08)$ & $-17.89(-1336.70-1300.92)$ & $1.09(0.99-1.19)$ & $0.99(0.95-1.03)$ \\
\hline $\begin{array}{l}\text { All indirect costs } \\
(95 \% \mathrm{Cl})\end{array}$ & $1947.09(950.67-2943.52)^{* *}$ & $355.04(-510.20-1220.28)^{*}$ & 1148.41 (-688.51-2985.33) & $1.12(1.04-1.20)^{* *}$ & $1.01(0.98-1.04)$ \\
\hline All costs $(95 \% \mathrm{Cl})$ & $3081.46(1526.96-4635.96)^{* * *}$ & $679.20(-560.11-1918.52)^{* *}$ & $1130.52(-1435.05-3696.09)$ & $1.11(1.04-1.19)^{* *}$ & $1.00(0.98-1.03)$ \\
\hline $\begin{array}{l}\text { Note } \\
\text { AD Alcohol depende } \\
\text { International Diagno } \\
\text { Statistical Manual of } \\
\text { For testing impact of } \\
{ }^{*} p<.05{ }^{* *} p<.011^{*} \\
\text { a Excess costs for GP } \\
\text { binary predictor (no } \\
\text { b Excess costs betwe } \\
{ }^{\circ} \text { The incidence risk ra }\end{array}$ & $\begin{array}{l}\text { c Interview ( } N=92), I R R \text { Incidence } \\
\text { ental Disorders, 5th edition, } 95 \% \\
\text { DD characteristics on different cost } \\
b<.001 \\
D \text { and CIDI AD diagnoses are pres } \\
\text { agnosis/diagnosis) among all pati } \\
\text { treated and untreated AD cases }\end{array}$ & $\begin{array}{l}\text { risk ratio, DSM-5 AUD criteria N } \\
\text { Cl } 95 \% \text { confidence interval } \\
\text { t variables, age and sex adjustec } \\
\text { sented in comparison to patient } \\
\text { ents } \\
\text { are presented. Results based on }\end{array}$ & $\begin{array}{l}(N=70), C I D I A D \text { Alcohol depend } \\
\text { lumber of alcohol use disorder } \mathrm{cr} \\
\text { d negative binomial regressions } \\
\text { ts without the respective diagnos }\end{array}$ & $\begin{array}{l}\text { were conducted. Leg } \\
\text { sis. Results based on } \\
\text { tor (untreated/treated) }\end{array}$ & $\begin{array}{l}\text { Composite } \\
\text { ne Diagnostic and } \\
\text { end of significance: } \\
\text { regression using } \\
\text { among all AD cases } \\
\text { nusing continuous }\end{array}$ \\
\hline
\end{tabular}

on any cost dimension (see Additional analyses), it is not surprising that the share of excess costs attributable to alcohol treatment is relatively small. Low treatment rates imply lower costs for alcohol-specific interventions but also result in high comorbidity and continuing impairment. In fact, previous studies have suggested to increase treatment coverage in order to bring about significant reductions in morbidity and mortality [60, 61], which we would expect to lead to a reduced economic burden.

Apart from costs for alcohol treatment, inpatient treatment and GP visits made up most of the excess direct costs. While alcohol is a component cause of over 200 health conditions [23, 62], AD is associated with a wide range of physical comorbidities in inpatient settings [8], and the present sample of $\mathrm{AD}$ cases was found to be comorbid with liver diseases and severe mental distress [57]. Thus, highly frequent health care resource utilization and associated costs among $\mathrm{AD}$ cases are not surprising and most likely not only attributable directly to alcohol problems, but to a significant extent to comorbidities associated with or caused by this condition. Therefore, our findings highlight and reiterate the necessity of preventing heavy drinking over time in order to reduce respective detrimental health consequences.

Half of the excess costs were due to increased rates of unemployment, early retirement, and disability. Further, absenteeism was also identified as important contributor to excess costs. While presenteeism was not part of cost calculations in this study, it was very common among $\mathrm{AD}$ cases. Some guidelines suggested the inclusion of presenteeism in the calculation of indirect costs [63] while others suggested not to do so [38]. In fact, many published studies on cost-of-illness of alcohol neglected this factor e.g. $[2,12,15,17]$ and only very few studies included presenteeism in their estimations e.g. [64]. Our work suggest that presenteeism is associated with $\mathrm{AD}$ and should therefore be included in future studies.

A major implication of this study concerns the observation that impaired productivity represents the largest share of the economic burden associated with $\mathrm{AD}$, confirming previous top-down estimations from Germany $[12,65]$ and elsewhere (for a review, see [66]). Public health efforts should aim at reducing this burden while acknowledging the bidirectional association of unemployment and heavy drinking $[67,68]$ and strategies to do so in primary health care settings have been proposed [69].

Sex-stratified cost estimations in our study suggest that excess costs mainly incurred among male AD cases in our study. This is not only due to males representing about two thirds of all AD cases, but rather to generally larger cost differences in most sectors between both sexes: Total direct costs were significantly increased in male but not in female AD cases, and excess costs were almost doubled among male compared to female $\mathrm{AD}$ cases. While we corroborate that female AD patients are less likely to receive treatment for their alcohol problems than male $\mathrm{AD}$ patients are [70], the greater picture is rather surprising. As the small number of females in this sample implies large confidence intervals and susceptibility to outliers, these results should be carefully interpreted as trends. However, the results point out that sex-stratified cost estimations are warranted and future research should follow up these preliminary observations. Distinct sex-specific patterns of mental [71] and somatic comorbidities [23] should be considered as potential explanations for differential cost discrepancies found in this study. 
Furthermore, our results indicate that most of the excess costs incurred among individuals aged 30 to 49, while no substantial cost differences was observed in younger or older cohorts. This effect is interesting and could likely be linked to mortality, which has been shown to be constantly high among young and middle aged individuals with alcohol use disorders, as opposed to the general population, for which mortality increases steadily with age [4]. High excess costs in combination with high mortality in these age groups support the need of initiating treatment earlier - before somatic comorbidities emerge and become life-threatening [28].

Lastly, results from additional analyses show that the economic burden is not only associated with DSM-IV AD diagnoses but also with GP AD diagnoses, which can be viewed as a validation for their diagnostic quality. In addition, DSM-5 AUD severity was also found to be associated with increased economic burden. Associations with direct costs were only found for GP AD diagnoses and future research should examine why associations with other AD characteristics, including treatment and drinking levels, remained insignificant. In this study, small sample sizes cannot be excluded as potential cause.

\section{Limitations}

For a variety of reasons, the estimates in this study are not directly comparable to a general population cost-ofillness study. The primary reason is that this study referred to a representative sample of primary care patients, which differs considerably in its distribution of sex and health measures from the general population. Further, the reported estimations do not consider intangible costs and costs associated with premature disability and presenteeism - measures that should be considered when estimating the economic burden of $\mathrm{AD}$ to the whole society. In addition, further wider social costs are evident as a result of alcohol related crime, both to the criminal justice system and also victim costs and further injury-related productivity costs through absenteeism. Although these go beyond the remit of the current study, crime costs form a substantial proportion of alcohol related societal costs [72-74]. Taken together, the figures of this study are likely underestimates and should not be generalized to the general population. Further, stratified analyses of age, sex, and AD characteristics should be interpreted cautiously as subgrouping results in smaller samples, which are more susceptible to outliers and thereby to erroneous inferences.

With regard to valuating productivity losses, we used the friction cost approach for absenteeism and considered transfer payments (benefits, taxation, insurances) for unemployment, disability and early retirement. This was a conservative decision avoiding the potential overestimation of the true cost of productivity losses as if using the human capital approach, and was believed to better represent the real costs of productivity losses than with the human capital approach, which shows the potential consequences of disease for an economy in a state of full employment equilibrium. The friction approach is also believed to prevent adverse equity implications $[51,56]$.

\section{Conclusions}

Despite the mentioned limitations, the present study corroborates the importance of the economic burden associated with $\mathrm{AD}$ as determined by previous general population top-down estimates by using a bottom-up approach: Total costs were $50 \%$ higher among patients with $\mathrm{AD}$ compared to patients without this diagnosis (excess costs: $1836 €$ per case), with excess costs mainly attributable to reduced productivity. We found high concentrations of AD-associated costs among males and patients aged 30 to 50 . Furthermore, DSM-5 AUD severity was also significantly linked to the economic burden. While we generally confirm previous estimations of ADassociated economic burden, we have also identified several discrepancies. Future cost-of-illness studies using a bottom-up approach in a general population sample may be able to examine possible reasons for these gaps, and they should consider presenteeism in their estimations.

\section{Additional files}

Additional file 1: Service Use Questionnaire adapted from the UK Alcohol Treatment Trials. (PDF 678 kb)

Additional file 2: Web Table 1: Description of unit costs in 2014-€. Web Figure 1: Estimating costs related to prescribed medication. (PDF $388 \mathrm{~kb}$ )

\section{Acknowledgements}

The APC study was financially supported by an investigator-initiated grant given to the last author and the GWT-TUD (Gesellschaft für Wissens- und Technologietransfer der TU Dresden mbH - company with limited liabilities for transferring knowledge and technology of the Dresden University of Technology) by Lundbeck (grant number 414209). The study sponsor has no role in study design, collection, analysis, nor interpretation of data. The study sponsor also had no role in the writing of the report nor the decision to submit the paper for publication. The corresponding author confirms that the authors had full access to the data in the study at all times, and had final responsibility for the decision to submit for publication.

\section{Availability of data and materials}

The dataset supporting the conclusions of this article is available in the figshare repository with the following DOI: 10.6084/m9.figshare.2069585. Access via: https://figshare.com/articles/APC_PC_SC_finalclean_dta/2069585.

\section{Authors' contributions}

JR conceptualized the study design and protocol and served as principal investigator. SP was responsible in developing the service use questionnaire. $J M$ and PL gathered information on unit costs. JM conducted all statistical analyses and drafted the manuscript. All authors contributed to the manuscript, revised it critically and approved of the final version. 


\section{Competing interest}

First author: reports receiving personal fees from Lundbeck, outside of the submitted work.

Second author: reports having been an employee of Lundbeck, outside of the submitted work.

Third author: reports no conflict of interest.

Fourth author: reports grants from GWT-TUD during the conduct of the study and grants, personal fees and serving as board member (Nalmefene) for Lundbeck, outside of the submitted work.

\section{Author details}

'Institute for Clinical Psychology and Psychotherapy, TU Dresden, Chemnitzer Str. 46, 01187 Dresden, Germany. ${ }^{2}$ Institute for Mental Health Policy Research, Centre for Addiction and Mental Health (CAMH), 33 Russell Street, Toronto, ON M5S 2S1, Canada. ${ }^{3}$ Department of Health Sciences, University of York, Heslington, York, UK. ${ }^{4}$ Campbell Family Mental Health Research Institute, CAMH, 250 College Street, Toronto, ON M5T 1R8, Canada. ${ }^{5}$ Institute of Medical Science (IMS), University of Toronto, Medical Sciences Building, 1 King's College Circle, Room 2374, Toronto, ON M5S 1A8, Canada. ${ }^{6}$ Department of Psychiatry, University of Toronto, 250 College Street, 8th Floor, Toronto, ON M5T 1R8, Canada. 'Dalla Lana School of Public Health, University of Toronto, 155 College Street, 6th Floor, Toronto, ON M5T 3M7, Canada.

\section{Received: 10 February 2016 Accepted: 23 August 2016} Published online: 31 August 2016

\section{References}

1. Rehm J, Anderson P, Barry J, Dimitrov P, Elekes Z, Feijão R, Frick U, Gual A, Gmel G, Kraus L, et al. Prevalence of and potential influencing factors for alcohol dependence in Europe. Eur Addict Res. 2015;21(1):6-18.

2. Rehm J, Shield KD, Rehm MX, Gmel G, Frick U. Alcohol consumption, alcohol dependence, and attributable burden of disease in Europe: potential gains from effective interventions for alcohol dependence. Toronto, Canada: Centre for Addiction and Mental Health; 2012.

3. Harris EC, Barraclough B. Excess mortality of mental disorder. BJP. 1998;173:11-53.

4. Roerecke M, Rehm J. Alcohol use disorders and mortality: a systematic review and meta-analysis. Addiction. 2013;108(9):1562-78.

5. Westman J, Wahlbeck K, Laursen TM, Gissler M, Nordentoft M, Hallgren J, Arffman M, Osby U. Mortality and life expectancy of people with alcohol use disorder in Denmark, Finland and Sweden. Acta Psychiatr Scand. 2015; 131(4):297-306

6. Samokhvalov AV, Popova S, Room R, Ramonas M, Rehm J. Disability associated with alcohol abuse and dependence. Alcohol Clin Exp Res. 2010; 34(11):1871-8

7. Rehm J, Allamani A, Elekes Z, Jakubczyk A, Landsmane I, Manthey J, Moreno-España J, Pieper L, Probst C, Snikere S, et al. General Practitioners Recognizing Alcohol Dependence: A Large Cross-Sectional Study in 6 European Countries. Ann Fam Med. 2015;13(1):28-32.

8. Schoepf D, Heun R. Alcohol dependence and physical comorbidity: Increased prevalence but reduced relevance of individual comorbidities for hospital-based mortality during a 12.5-year observation period in general hospital admissions in urban North-West England. European Psychiatry. 2015;30(4):459-68.

9. Odlaug BL, Gual A, DeCourcy J, Perry R, Pike J, Heron L, Rehm J. Alcohol Dependence, Co-occurring Conditions and Attributable Burden. Alcohol Alcohol. 2016;51(2):201-9.

10. World Health Organisation. WHO guide to identifying the economic consequences of disease and injury. Geneva: WHO Press; 2009.

11. Mohapatra S, Patra J, Popova S, Duhig A, Rehm J. Social cost of heavy drinking and alcohol dependence in high-income countries. Int j public health. 2010;55(3):149-57.

12. Konnopka A, König H-H. Direct and Indirect Costs Attributable to Alcohol Consumption in Germany. Pharmacoeconomics. 2007;25(7):605-18.

13. Horch K, Bergmann E. Berechnung der Kosten alkoholassoziierter Krankheiten. Bundesgesundheitsbl Gesundheitsforsch Gesundheitsschutz. 2003;46(8):625-35.

14. Effertz T, Mann K. The burden and cost of disorders of the brain in Europe with the inclusion of harmful alcohol use and nicotine addiction. Eur neuropsychopharmacol: j Eur Col Neuropsychopharmacol. 2013;23(7):742-8.
15. Anderson P, Baumberg B. Alcohol in Europe: A public health perspective. London: Institute of Alcohol Studies; 2006.

16. Shield KD, Rehm MX, Rehm J. Social costs of addiction in Europe. In: Anderson P, Rehm J, Room R, editors. The impact of addictive substances and behaviours on individual and societal well-being. Oxford, UK: Oxford University Press; 2015. p. 181-8.

17. Laramee P, Kusel J, Leonard S, Aubin HJ, Francois C, Daeppen JB. The economic burden of alcohol dependence in Europe. Alcohol Alcohol. 2013; 48(3):259-69.

18. Rehm J, Kehoe T, Gmel G, Stinson F, Grant B, Gmel G. Statistical modeling of volume of alcohol exposure for epidemiological studies of population health: the US example. Popul Health Metrics. 2010;8:3.

19. Sortso C, Green A, Jensen PB, Emneus M. Societal costs of diabetes mellitus in Denmark. Diabetic med: j British Diabetic Assoc. 2015;33(7):877-85.

20. Parise H, Laliberte F, Lefebvre P, Duh MS, Kim E, Agashivala N, Abouzaid S, Weinstock-Guttman B. Direct and indirect cost burden associated with multiple sclerosis relapses: excess costs of persons with MS and their spouse caregivers. J Neurol Sci. 2013;330(1-2):71-7.

21. Olesen J, Gustavsson A, Svensson M, Wittchen HU, Jonsson B, group Cs, European Brain C. The economic cost of brain disorders in Europe. Eur J Neurol. 2012;19(1):155-62.

22. Grant BF, Dawson DA, Stinson FS, Chou SP, Dufour MC, Pickering RP. The 12-month prevalence and trends in DSM-IV alcohol abuse and dependence: United States, 1991-1992 and 2001-2002. Drug Alcohol Depend. 2004;74(3): 223-34.

23. Shield KD, Parry C, Rehm J. Chronic Diseases and Conditions Related to Alcohol Use. Alcohol Research: Current Reviews. 2013;35(2):155-73.

24. Manthey J, Gual A, Jakubczyk A, Pieper L, Probst C, Struzzo P, Trapencieris M, Wojnar M, Rehm J. Alcohol use disorders in Europe: A comparison of general population and primary health care prevalence rates. Journal of Substance Use. 2016;21(5):478-84.

25. American Psychiatric Association. Diagnostic criteria from DSM-IV-TR. Washington, D.C.: American Psychiatric Association; 2000

26. American Psychiatric Association. Diagnostic and Statistical Manual of Mental Disorders. 5th ed. Washington, DC: American Psychiatric Association; 2013

27. Rehm J, Marmet S, Anderson P, Gual A, Kraus L, Nutt DJ, Room R, Samokhvalov AV, Scafato E, Trapencieris M, et al. Defining substance use disorders: do we really need more than heavy use? Alcohol Alcohol. 2013; 48(6):633-40.

28. Rehm J, Manthey J, Struzzo P, Gual A, Wojnar M. Who receives treatment for alcohol use disorders in the European Union? A cross-sectional representative study in primary and specialized health care. Eur psychiatry: $j$ Assoc Eur Psychiatrists. 2015;30(8):885-93.

29. Grant BF, Goldstein RB, Saha TD, Chou SP, Jung J, Zhang H, Pickering RP, Ruan WJ, Smith SM, Huang B, et al. Epidemiology of DSM-5 Alcohol Use Disorder: Results From the National Epidemiologic Survey on Alcohol and Related Conditions III. JAMA psychiatry. 2015;72(8):757-66.

30. Wang C, Xue H, Wang Q, Hao Y, Li D, Gu D, Huang J. Effect of drinking on all-cause mortality in women compared with men: a meta-analysis. J Women's Health. 2014:23(5):373-81.

31. Alonso J, Angermeyer MC, Bernert S, Bruffaerts R, Brugha IS, Bryson $H$, de Girolamo G, de Graaf R, Demyttenaere K, Gasquet I, et al. Use of mental health services in Europe: results from the European Study of the Epidemiology of Mental Disorders (ESEMeD) project. Acta Psychiatr Scand. 2004;109:47-54

32. Rehm J, Allamani A, Elekes Z, Jakubczyk A, Manthey J, Probst C, Struzzo P, Della Vedova R, Gual A, Wojnar M. Alcohol dependence and treatment utilization in Europe - a representative cross-sectional study in primary care. BMC Fam Pract. 2015;16(1):90.

33. Lachner $G$, Wittchen $H-U$, Perkonigg A, Holly A, Schuster P, Wunderlich U, Türk D, Garczynski E, Pfister H. Structure, Content and Reliability of the Munich-Composite International Diagnostic Interview (M-CIDI) Substance Use Sections. Eur Addict Res. 1998:4:28-41.

34. Knappe S, Runge J, Beesdo K, Jacobi F, Wittchen H-U. Diagnosing mental disorders: gold or tin standard? - Critical comments on standardized diagnostic interviews and clinical routine diagnoses. Psychother Psychosom Med Psychol. 2008:58(2):72-5.

35. Greenfield TK, Kerr WC. Alcohol measurement methodology in epidemiology: recent advances and opportunities. Addiction. 2008;103(7): 1082-99. 
36. Üstün TB, Kostanjsek N, Chatterji S, Rehm J. Measuring health and disability: manual for WHO Disability Assessment Schedule WHODAS 2.0. Geneva: World Health Organization; 2010.

37. Ukatt Research Team. Cost effectiveness of treatment for alcohol problems: findings of the randomised UK alcohol treatment trial (UKATT). BMJ. 2005; 331(7516):544

38. Krauth C, Hessel F, Hansmeier T, Wasem J, Seitz R, Schweikert B. Empirical standard costs for health economic evaluation in Germany - a proposal by the working group methods in health economic evaluation. Gesundheitswesen. 2005;67(10):736-46.

39. Statistisches Bundesamt. Verbraucherpreisindex für Deutschland. 2015. https://www.destatis.de/DE/ZahlenFakten/GesamtwirtschaftUmwelt/Preise/ Verbraucherpreisindizes/Tabellen_NerbraucherpreiseKategorien.html. Accessed 25 Nov 2015

40. Kassenärztliche Bundesvereinigung: Einheitlicher Bewertungsmaßstab. Stand: 1 Quartal 2012. Berlin: Kassenärztliche Bundesvereinigung; 2012.

41. Gesundheitsberichterstattung des Bundes. Mitglieder und mitversicherte Familienangehörige der gesetzlichen Krankenversicherung am 1.7. eines Jahres. 2015. www.gbe-bund.de. Accessed 10 Dec 2015.

42. Gesundheitsberichterstattung des Bundes. Privaten Kranken- und Pflegeversicherung, Versicherte. 2015. www.gbe-bund.de. Accessed 10 Dec 2015.

43. KV Berlin. Vergütungsliste Ergotherapie. 2015. https://www.kvberlin.de/ 20praxis/50verordnung/20heilmittel/hm_verguetung/verguetung_ergo.pdf. Accessed 12 Oct 2015

44. vdek. Daten zum Gesundheitswesen: Versicherte. 2015. http://www.vdek. com/presse/daten/b_versicherte.html. Accessed 12 Oct 2015.

45. vdek. Vergütungsvereinbarung gemäß § 125 SGB V für die Abrechnung physiotherapeutischer Leistungen, Massagen und medizinischer Bäder. 2015. https://www.vdek.com/vertragspartner/heilmittel/rahmenvertrag/_jcr_ content/par/download_18/file.res/Verg\%C3\%BCtungsvereinbarung_Ost_ 2015_UF.pdf. Accessed 25 Aug 2016.

46. Fachverband Deutscher Heilpraktiker. Gebührenverzeichnis für Heilpraktiker (GebüH). 2002. http://www.heilpraktiker.org/files/seiteninhalt/inhaltsseiten/ c_fuer_heilpraktiker/cf-fuer-mitglieder-intern/cf-02-versicherungsfragen/cf02-01-01-gebueh-85-2002-final.pdf.Accessed 26 Oct 2015.

47. GENESIS-Online. VGR des Bundes - Bruttolöhne und -gehälter: Deutschland, Jahre, Wirtschaftsbereiche. 2015. https://www.destatis.de/DE/Startseite.html. Accessed 10 Dec 2015.

48. Rote Liste ${ }^{\circledR}$. Arzneimittelverzeichnis Deutschland. 2015. http://www.roteliste.de/. Accessed 09 Jul 2015.

49. World Health Organization. Introduction to Drug Utilization Research. Geneva: World Health Organization; 2003.

50. DRG Research Group. PEPP-Webgrouper Version 2015. 2015. http://drg.unimuenster.de/index.php?option=com webgrouper\&view=webgrouper\&ltemid=112. Accessed 29 Jul 2015.

51. Koopmanschap MA, Rutten FF, van Ineveld BM, van Roijen $L$. The friction cost method for measuring indirect costs of disease. J Health Econ. 1995; 14(2):171-89.

52. Statistisches Bundesamt: Statistisches Jahrbuch 2014. In: Deutschland und Internationales. Wiesbaden: Statistisches Bundesamt; 2014.

53. Institut für Arbeitsmarkt und Berufsforschung. Gesamtfiskalische Kosten der Arbeitslosigkeit im Jahr 2013 in Deutschland. 2014. http://doku.iab.de/ arbeitsmarktdaten/Kosten_ALO_2013.pdf. Accessed 12 Oct 2015.

54. Deutsche Rentenversicherung. Rentenversicherung in Zahlen 2015. 2015 http://www.deutsche-rentenversicherung.de/Allgemein/de/Inhalt/6_Wir_ ueber_uns/03_fakten_und_zahlen/03_statistiken/02_statistikpublikationen/ 02_rv_in_zahlen.pdf?_blob=publicationFile\&v=21. Accessed 12 Oct 2015.

55. Hilbe JM. Modeling Count Data. Cambridge: Cambridge University Press; 2014.

56. Drummond MF, Sculpher MJ, Torrance GW. O'Brien BJ, Stoddart GL: Methods for the Economic Evaluation of Health Care Programmes. 3rd ed. New York: Oxford University Press Inc:; 2005.

57. Trautmann S, Pieper L, Kuitunen-Paul S, Manthey J, Wittchen H-U, Bühringer $\mathrm{G}$, Rehm J: Prevalence and treatment rates of alcohol use disorders in primary care in Germany. Sucht. accepted.

58. Luciano A, Meara E. Employment status of people with mental illness: national survey data from 2009 and 2010. Psychiatr Serv. 2014;65(10):1201-9.

59. Wedegaertner F, Arnhold-Kerri S, Sittaro N-A, Bleich S, Geyer S, Lee WE. Depression- and anxiety-related sick leave and the risk of permanent disability and mortality in the working population in Germany: a cohort study. BMC Public Health. 2013;13:145.
60. Rehm J, Shield KD, Gmel G, Rehm MX, Frick U. Modeling the impact of alcohol dependence on mortality burden and the effect of available treatment interventions in the European Union. Eur neuropsychopharmacology: j Eur Col Neuropsychopharmacology. 2013; 23(2):89-97.

61. Cook S. Alcohol Dependence and Mortality: Implications for Treatment. EBioMed. 2015;2(10):1281-2.

62. World Health Organization. Global status report on alcohol and health 2014 Geneva, Switzerland: WHO Press; 2014.

63. Single E, Collins D, Easton B, Harwood H, Lapsley H, Kopp P, Wilson E. International guidelines for estimating the costs of substance abuse. 2nd ed. Geneva: Wold Health Organization; 2003

64. Rehm J, Baliunas D, Brochu S, Fischer B, Gnam W, Patra J, Popova S, Sarnocinska-Hart A, Taylor B. The Costs of Substance Abuse in Canada 2002. Ottawa: Canada Centre for Substance Abuse; 2006.

65. Brecht JG, Poldrugo F, Schädlich PK. Alcoholism: The Cost of Illness in the Federal Republic of Germany. Pharmacoeconomics. 1996;10(5):484-93.

66. Thavorncharoensap M, Teerawattananon Y, Yothasamut J, Lertpitakpong C, Chaikledkaew U. The economic impact of alcohol consumption: a systematic review. Subs abuse treatment, prevention, policy. 2009;4:20.

67. MacDonald Z, Shields MA. Does problem drinking affect employment? Evidence from England. Health Econ. 2004;13(2):139-55.

68. Mossakowski KN. Is the duration of poverty and unemployment a risk factor for heavy drinking? Soc Sci Med. 2008;67(6):947-55.

69. Rehm J, Anderson P, Manthey J, Shield KD, Struzzo P, Wojnar M, Gual A. Alcohol Use Disorders in Primary Health Care: What Do We Know and Where Do We Go? Alcohol Alcohol. 2015; epub ahead of print.

70. Alvanzo AA, Storr CL, Mojtabai R, Green KM, Pacek LR, La Flair LN, Cullen BA, Crum RM. Gender and race/ethnicity differences for initiation of alcoholrelated service use among persons with alcohol dependence. Drug Alcohol Depend. 2014;140:48-55

71. Goldstein RB, Dawson DA, Chou SP, Grant BF. Sex differences in prevalence and comorbidity of alcohol and drug use disorders: results from wave 2 of the national epidemiologic survey on alcohol and related conditions. J Stud Alcohol Drugs. 2012;73(6):938-50.

72. Harwood HJ, Fountain D, Livermore G. Cost estimates for alcohol and drug abuse. Addiction. 1999:94(5):631-47.

73. NHS National Institute for Health and Clinical Excellence. Alcohol-use disorders: preventing harmful drinking. London: National Institute for Health and Clinical Excellence; 2010.

74. Public Health Information and Research Branch. Social Costs of Alcohol Misuse in Northern Ireland for 2008/09. Belfast: Department of Health, Social Services and Public Safety; 2010.

\section{Submit your next manuscript to BioMed Central and we will help you at every step:}

- We accept pre-submission inquiries

- Our selector tool helps you to find the most relevant journal

- We provide round the clock customer support

- Convenient online submission

- Thorough peer review

- Inclusion in PubMed and all major indexing services

- Maximum visibility for your research

Submit your manuscript at www.biomedcentral.com/submit 